\title{
The estimation of Iran's macroeconomics instability index
}

\author{
Abdolmajid Ahangari ${ }^{\mathrm{a}}$, Aziz Arman ${ }^{\mathrm{a}}$ and Aziz Saki ${ }^{\mathrm{b}^{*}}$
}

${ }^{a}$ Associate Professor of Economics, Shahid Chamran University, Ahvaz, Iran

${ }^{b}$ Master of Economics, Shahid Chamran University, Ahvaz, Iran

\section{CHRON I C E A A S TRACT}

Article history:

Received December 28, 2013

Accepted 28 March 2014

Available online

April 112014

Keywords:

Macroeconomics Instability Index

Inflation

Deficit

External Debt

Exchange Rate Premium (ERP)

\begin{abstract}
In this study, we estimate the macroeconomics instability index over the period 1963-2003. Using the definition of Fischer and Bleaney, the study calculates the "macroeconomics instability index". In order to compute the macroeconomics instability index, four sub-indices of inflation rate, the fractional ratio of budget to the gross national product, the ratio of foreign debt to the gross national product, and the ratio of the free exchange rate to the official exchange rate as the determinant variables of the macroeconomics instability are considered. Then, the study estimates the equations for long-term processes for each variable and determines the deviations from the real values. We also obtain the time series for the macroeconomics instability index, using the calculated simple mean of the variables' deviations and discuss the results.
\end{abstract}

\section{Introduction}

The importance of macroeconomic stability became the center of attention for many economists right after publishing a report by the international bank on this subject in 1991. The report analyzed the performance of countries within 1970's and 80's and the results showed that the countries who have economic stability with appropriated and coordinated government policies, have got better performance in comparison with those without the stability (International bank, 1991). After the focus of the International bank on the economic stability, some of the economists started to study the effects of government policies on economic growth, namely Fischer (1991) and Fischer and Modigliani (1978), Ghura et al. (1994), and Bleaney (1996). In this paper, we estimate the macroeconomics instability index in Iran over the period 1961-2003. After the introduction, the article respectively presents previous studies, the concept of the macroeconomics instability, the causes of the macroeconomics instability, introducing a model and estimation it, and finally the conclusion and recommendations are given at the end to summarize the contribution of the paper. 


\section{Previous studies}

Fischer (1991) and Fischer and Modigliani (1978) are believed the first people who realized the importance of the macroeconomic stability, and explicitly focused on it. In a national study in 1991, they introduced and estimated the well-known instability indexes including inflation, budget deficit and foreign debt. The results indicated that growth per capita maintained a negative relationship with inflation, budget deficit and foreign debt. Ghura et al. (1994) evaluated the performance of African countries in their research by analyzing the data from 41 countries over the period 1986-1993. They reported the variables of inflation rate, budget deficit and exchange rate divergence as the indexes of instability. They also reported that the countries with macroeconomic stability had been able to maintain a higher growth rate, and more internal saving than the instable countries. Bleaney (1996) investigated 41 developing countries over the period 1980-90 and studied whether constant budget deficit, growing inflation, and wrong policies could be reasons for the weak management of macroeconomics and the instability of the macroeconomic environment. The study completely separated the introductive variables of macroeconomics instability from the other explanatory components and demonstrated them, distinctively. Ismihan et al. (2005) reported that chronic macroeconomics instability in Turkey had a serious impact on the structure of capital and growth.

\section{The concept of macroeconomics instability}

According to World Bank (1991) the concept of macroeconomics instability is defined as "low and stable inflation, which is only caused by fiscal principle in public section, is the best basis for macroeconomic stability which invigorate the motivations for investment and saving. The World Bank also emphasized on budget deficit, foreign debt and the instability of exchange rates alongside exchange rate as influential factors in macroeconomics instability". In examining the performance of East Asian economies, the World Bank, with the emphasis on macroeconomic stability, specified four major conditions including managing budget deficits, keeping inflation low or moderate rate, keeping control of foreign debt and currency management (World Bank, 1993). After this report, the stable macroeconomic environment became the center of attention and interest of some researchers, and each provided a definition of it and gradually, a consensus is reached in this matter. Although high and growing inflation rate and instability are the most important factors for macroeconomics instability based on the World Bank, it is still clear from the above definitions that this concept goes beyond inflation and solely emphasizing on that could be misleading.

In order to measure macroeconomic instability indexes as proxy variables, Bleaney (1996) suggested emphasis on the quality of macroeconomic management. He believed that strong management of macroeconomics could lead to stable environment and poor management may lead to an unstable environment. Instability, according to the definition, is the sequence of shortages and surpluses. In other words, instability is an increase or decrease of the values of a variable, around the values of its process. Different criteria have been used to measure instability, namely Kopac index, moving average index, Glezakos index, Dawe index, and the real value standard deviation index of the estimated process. With regard to the present statistics, the aim of the study is to use the real value standard deviation index to estimate the instability of a number of economic indexes and compute macroeconomic index. In order to compute the real value standard deviation index of the estimated process, the following equation is used:

$I X_{t}=X_{t}-T X_{t}$,

where $I X_{t}$ represents Instability index of variable $X_{t}, X_{t}$ states the actual values of the variable at time $\mathrm{t}$ and $T X_{t}$ is the estimated values of variable $X_{t}$ depending on a specific form of the time process equation. 
Time process equation is expressed in different forms. In this study, the form of degree $n$ is used, which is more applicable in empirical equations. Equation of the form of degree $n$ is as follows,

$T X_{t n}=a_{0}+a_{1} t+a_{2} t^{2}+a_{3} t^{3}+\ldots+a_{n} t^{n}+e_{t}$,

where $T X_{m}$ is the estimated values of variable $X_{t}$ at time $t$ in the form of degree $n, t$ represents time and $e_{t}$ states perturbation sentence. To explain Eq. (1), we can argue that the estimated values of $T X_{t}$ is associated with some potential values, where $X_{t}$ has to have regarding the growth rates during the time or period of the study and any kind of deviation from these potential values indicates fluctuations of variable $X_{t}$ in time. The deviations are calculated in ant time section using the Eq. (2), and having done these computations, a time series of the instability indexes is obtained for the variable $X_{t}$ (Glezakos, 1973). This paper uses the definitions of Bleaney (1996) and Glezakos definition (1973) defines four factors of inflation rate, the instability in ratio of budget deficits to GDP, the instability in ratio of foreign debt to GDP, and instability in the exchange rate premium (the ratio of the free exchange to official exchange rate) to estimate the macroeconomics instability index.

\section{The determinants of macroeconomics instability}

\subsection{Exchange rate}

If exchange rate has severe fluctuation, due to the time passed between the moments of signing contracts and the time of export or import, export incomes and the cost of imported goods will fluctuate as well. Such fluctuations cause changes in prices and inflation rate and generally fluctuations in macroeconomic variables. This results in uncertain atmosphere and stock games and speculations in the currency market and more generally in the country's economy. Widespread speculations in the currency market, which is affected by exchange rate fluctuations, causes liquidity to be led into brokers and intermediates and pseudo-mediated activities to grow. Of course, this speculation is not limited only to the currency market, it spreads on the goods' market as well, because currency fluctuations at first, causes fluctuations in the price of commodities, which has a foreign origin, and then it even spreads to other commodities, too.

Instability in the exchange rate could be due to several factors. Since several developing countries depend on economic structures, international shocks can cause instability in the exchange incomes and exchange rate in these countries. In addition, performing economic adjustments can be another cause of instability in the exchange rate. The experiences of many countries who have taken major actions towards economic adjustments revealed some successes and some failures in this process. The countries with proper structures in the area of economic decision-making systems, regulations, value and executive and management and supervision systems, perceive their initial conditions of the economy and are aware of their capacity, classification their economic goals based on priorities. They can avoid ambitious and far-fetched goals, possess adequate economic tools, and have proper political and social stability, can take major and thriving steps towards economic development in all aspects (Tanzi \& Davoodi, 1998). However, if the above-mentioned factors are neglected, the economic adjustment will lead to instability in the currency market.

Fluctuations in the currency market can ultimately lead to the "indexation" of products and some financial assets such as gold to the dollar. "Indexation" is associated with a situation in which the retail and wholesale prices and relative wages, are evaluated in comparison with unofficial exchange rate or inflation speculations due to instant exchange rate fluctuation, and this is the most unstable situation where intermediation and speculation lead the capital sources from the real section to the business and intermediation section. Moreover, manufacturers find their benefit in increasing their inventories and offering it in future, and there will be a recession together with inflation. In this situation, the price of goods determines and fluctuates in proportion to the exchange rate in unofficial market (Tanzi \& Davoodi, 1998). There are several indicators to demonstrate the stability or 
instability of exchange rates; one of which is the ratio of free exchange rate to official exchange rate that is known as the exchange rate premium.

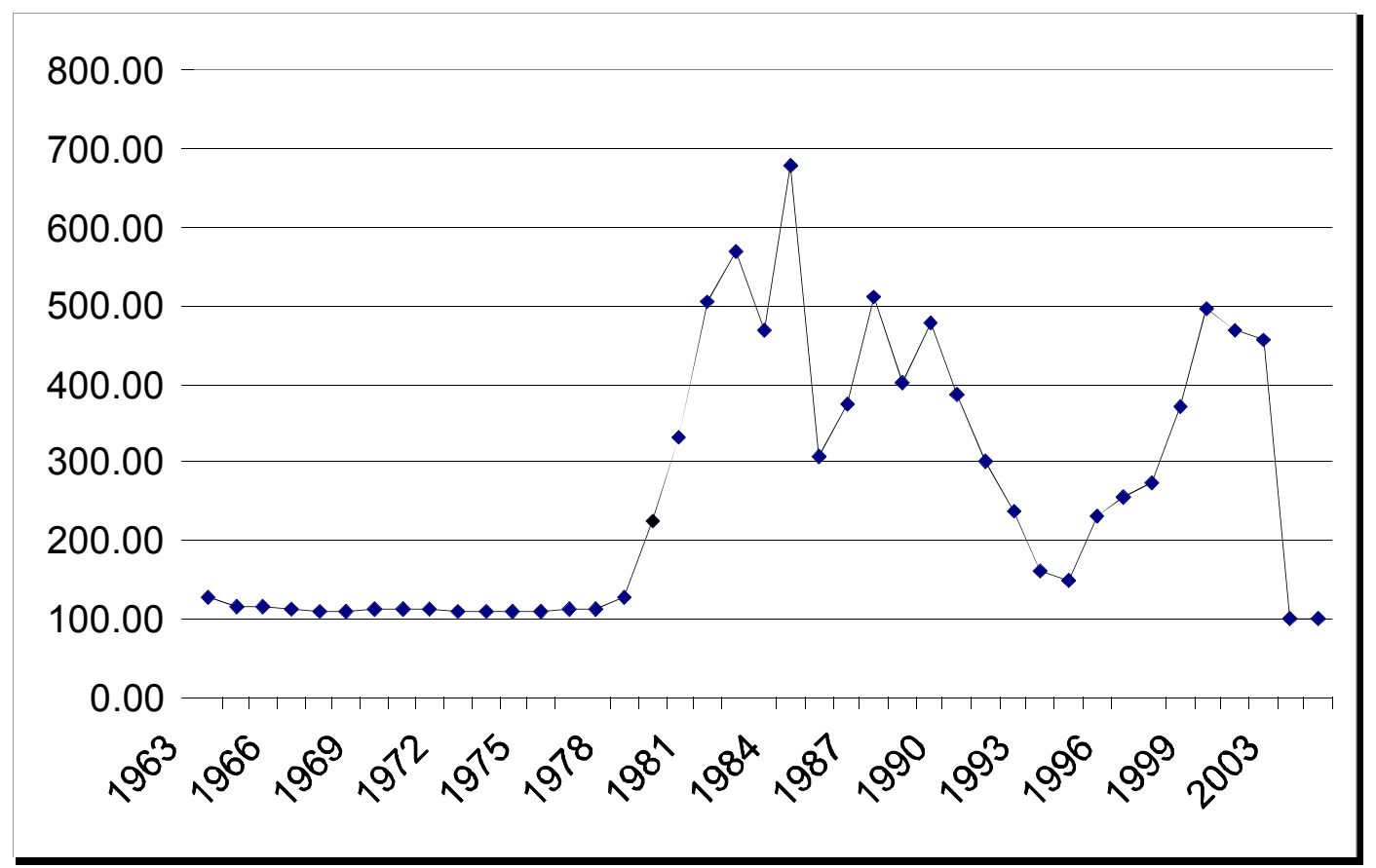

Fig. 1. Time series of the exchange rate premium (percentage) (Source: Based on the data from the Central Bank OF Islamic Republic of Iran)

Fig. 1 is associated with the curve demonstrating to the percentage of change in the exchange rate premium; it shows that up to 1977 exchange rate premium had a stable condition with only a few insignificant changes, but since 1977, the premium exchange rate fluctuations start to increase. The changes of the exchange rate premium had been severe from 1977 to 2001, except for the years when the official exchange rate was close to the free exchange rate because of government policies. It has been in a way that we can say the fluctuation of this variable has played a role in the budget deficits and inflation rates, and more importantly in the macroeconomics instability, in the last two decades. While up to year 1978, the free exchange rate increased at a maximum of 1.3 times more than the official rate, in the next years it increased as 2, 3, 4, 5 and 6 times more than that, until in 1987 it reached its highest level in the period of the study that is 6.78 times more. In the last two decades, except for the years that the official exchange rate devaluated, the exchange rate premium has been considerable. More specifically, the exchange rate premium had been about 1.14 in the period of 1963-78, while between 1979 and 2003 the annual of the free to official exchange rate ratio had been about 3.53. To sum up we can say that:

1. The exchange rate premium had a stable and consistent rate from 1963 to 1975 Percentage changes in the exchange rate premium for these years were 1.14 percent. However, the fluctuations of exchange rate premiums have started to increase slightly since 1974.

2. The fluctuations in the exchange rate premium have been considerable from 1977 to 2001 . Percentage changes in the exchange rate premium in these years increased to 3.53 percent.

\subsection{Inflation rate instability}

Prices' instability is one of the major economic problems in most countries, especially developing countries, and could be due to several factors. Price instability is often indicated by inflation while growth in liquidity, exchange rate fluctuations in official and nonofficial markets and inflation 
predictions can be considered as the most important factors forming inflation (Tanzi \& Davoodi, 1998). There are literally various theories about the impacts of inflation on investment. Some economists are of the opinion that with the increase in the general price level or inflation, the present values will also increase. Thus, at that level of interest rates and the general price level increase, investment will rise. In addition, the consistent increase of prices changes the revenue distribution, which would benefit firms with higher revenue, and since with the revenue increase, the final tendency to consume decreases, therefore with the increase in the savings of the higher-revenue group, the possibility of investment is more included through creating more credit for the internal sources. On the other hand, high rates of inflation is considered as one of the instability indexes in macroeconomics and it increases the risk of long-term investment projects and creates mistrust to the benefits and prices, and by increasing the mistrust, decreases the investments. As Fig. 2 shows, it is clear that up to year 1970, except for a year or two, the inflation rate in Iran had been on a very low level, and until 1972, it still was a one-digit number. Therefore, we can say that until year 1972, macroeconomic environment can be relatively explained as stable. However, since 1973the inflation rate became and stayed two-digit in all years except for two years. In 1995, the inflation rate of 49.4 percent became the highest level that it ever was during the years under the study.

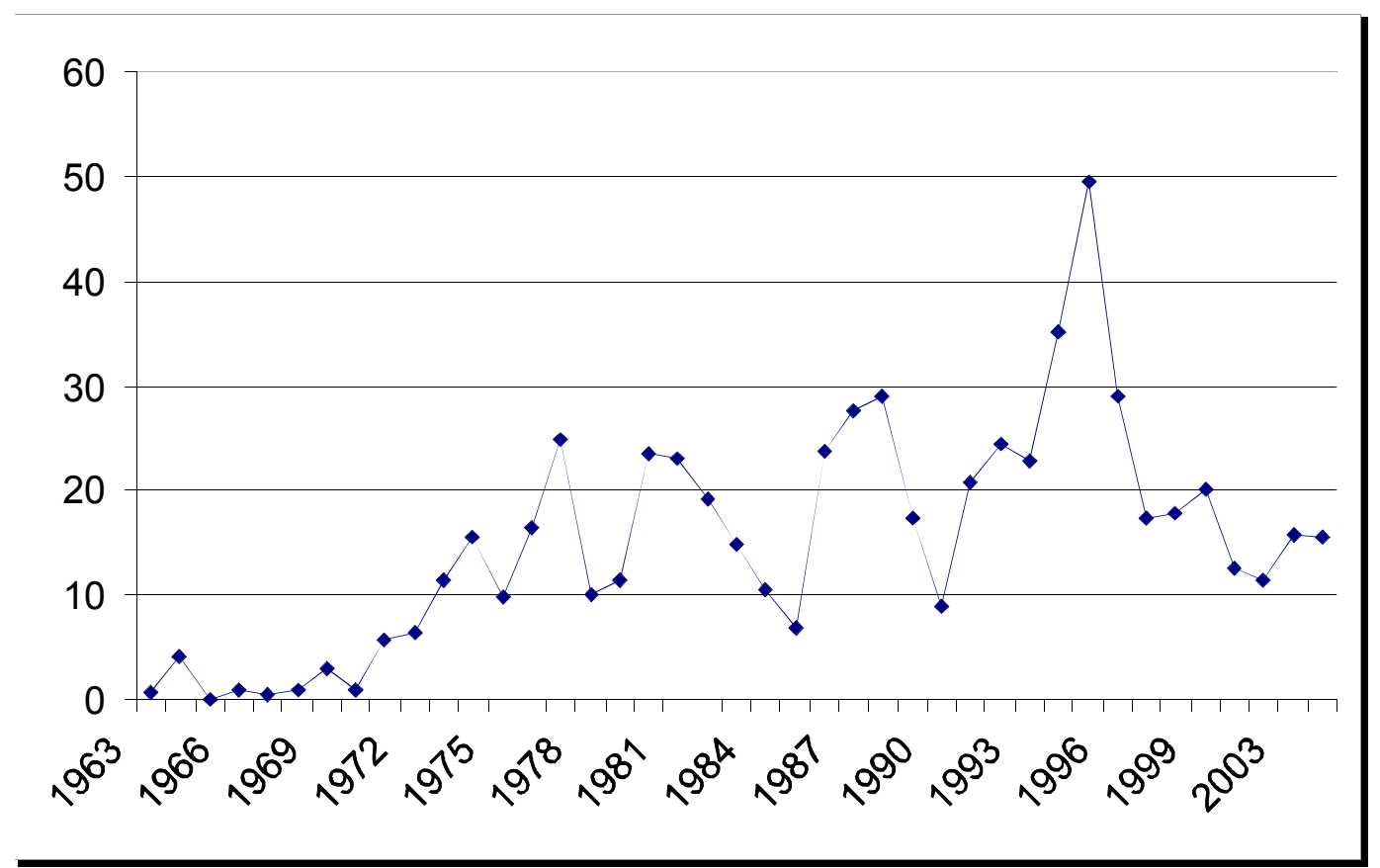

Fig. 2. Time series of the inflation rate (percentage) Source: Based on data from the Central Bank of Islamic Republic of Iran

The analysis of changes of consumer price index in different periods shows that the average inflation rate from 1963 to , has been 9.96 percent, and in the years after the Revolution, that is 1979 to 2001 it has been 20.32 percent, and within 1980-1987, 19.8 percent.

\subsection{Foreign debt instability}

In addition to the inflation rate, budget deficits, and exchange rate instability, the World Bank also emphasizes on foreign debt as another factor influencing macroeconomics instability (World Bank, 1991). High external debt relative to production influences on private investments negatively in a variety of ways:

1. The resources that are used in the repayment of foreign debts, may increase government investment and finally decrease private investment. 
2. High ratio of debt to production (and high rates of repayment associated with it) can lead internal enterprises to transfer their funds abroad, and the reason for matter is the fear of future tax liabilities, in order to meet the mentioned debt. This will lead to a reduction in private investment.

3. High foreign debt may decrease interest is in direct foreign investments. In the case that direct foreign investment, is complementary for private investments, this can result in private investment reduction.

The total ratio of different foreign debts to export and services or GNP, the ratio of annual repayment and debt rate and portions of different foreign debts for the country's economy such as macroeconomic environment, follows very important points. Negligence in foreign debt management can quickly result in economic instability. The index of foreign debt to GDP ratio is used in this study in order to analyze the condition of Iran's foreign debts.

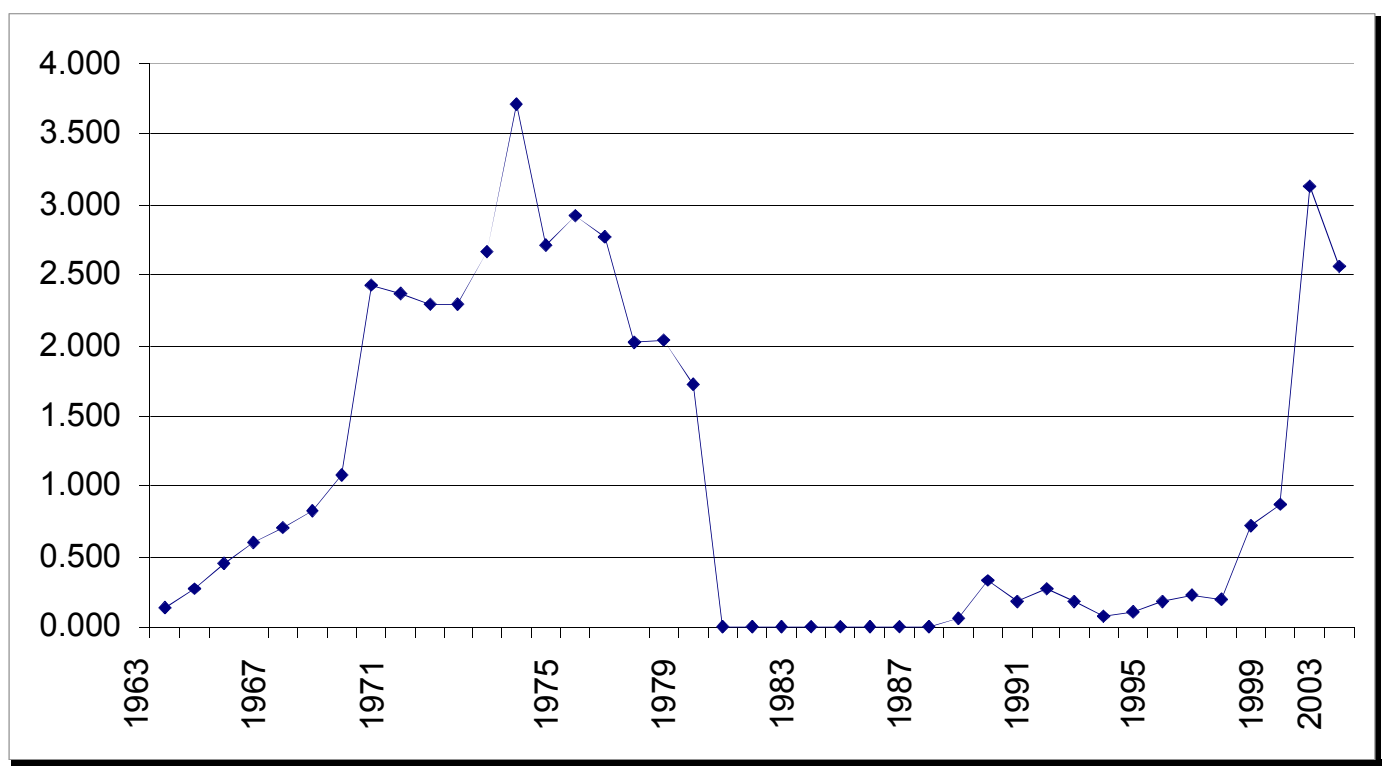

Fig. 3. Time series of the ratio of foreign debt to GDP (percentage) Source: Based on data from the Central Bank of Islamic Republic of Iran

\subsection{Budget deficit instability}

Given the long history of budget deficit in Iran and its effect on economic variables, it is essential to investigate this effect on private investments while making major economic policies. Budget deficit is created by an imbalance between sources and budget consumption. The sources of income for country budget depend on incomes earned directly or indirectly from gas and oil export. About budget consumption also the government duties in Iran has been constantly expanding regardless of the capacity of budget income, and this has put the burden of great commitments related to the expenses on the government's shoulders (Rangriz \& Khorshidi, 2008, p. 247). As can be seen in all these years budget deficits of the government existed. We use the fractional ratio of the budget deficit to GDP index to study the budget deficit condition better. With 16.99 percent in 1980, it reached to its highest value during the time under the study. The fractional ratio did not have an entirely increasing trend in 1963-2003, however, such a trend is observed in certain intervals: Between 1963 and 1972, the budget deficit ratio increased from 2.04 percent with fluctuations to 9.16. This trend is also seen between 1973 and 1978 moving from 3.18 percent to 12.16. Fig. 5 shows that between years 1963 to 2003 the fluctuations range of the budget deficit fractional ratio has been generally increasing. 


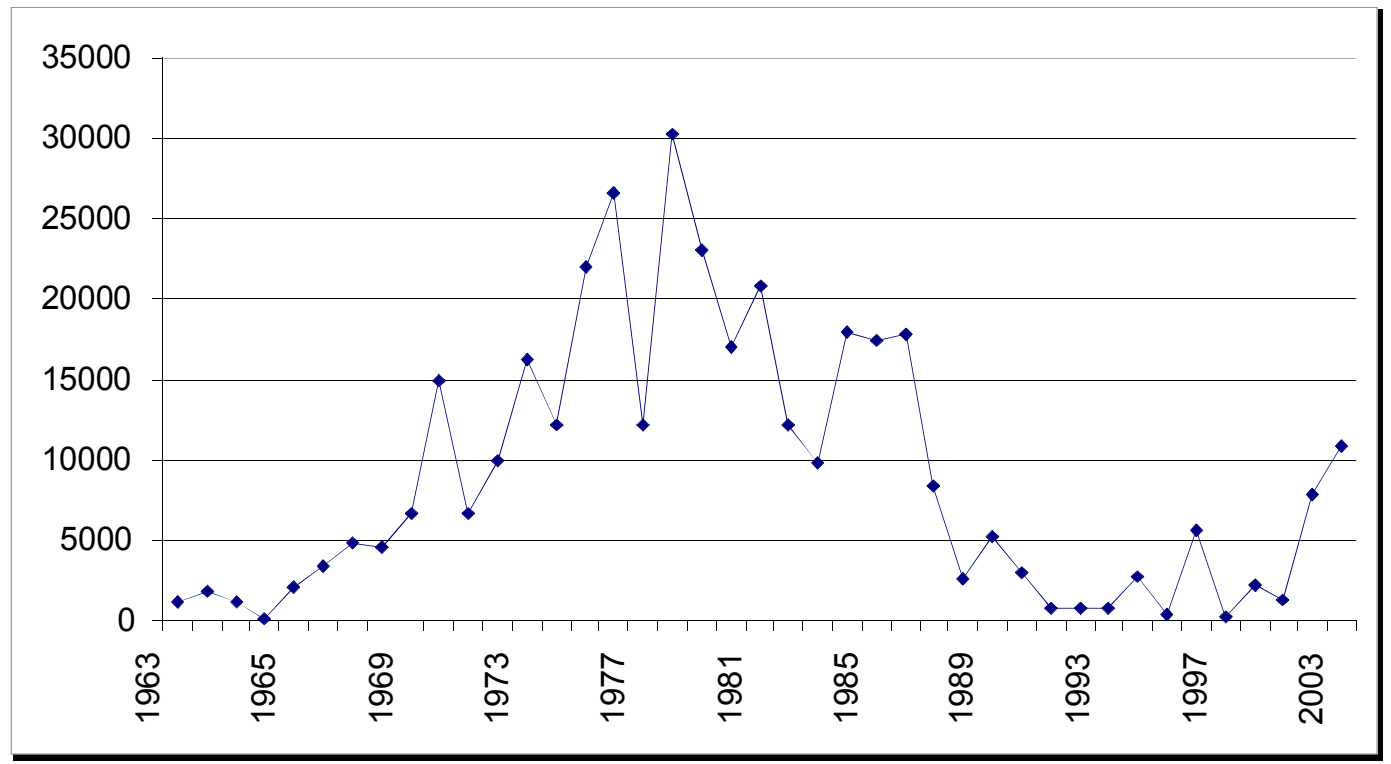

Fig. 4. Time series of the budget deficit in billion Rials (In constant prices of 1997) Source: Based on data from the Central Bank of Islamic Republic of Iran

In the subsequent years of 1981 to 2003 however, rather than the increasing trend, some changes are seen in the budget deficit in some years. On average, the fractional ratio of budget deficit to GDP is 4.48 percent in the years before the Revolution, that is 1963-1978, and increases to 5.17 in years 1979 to 1998 to 17.5 .

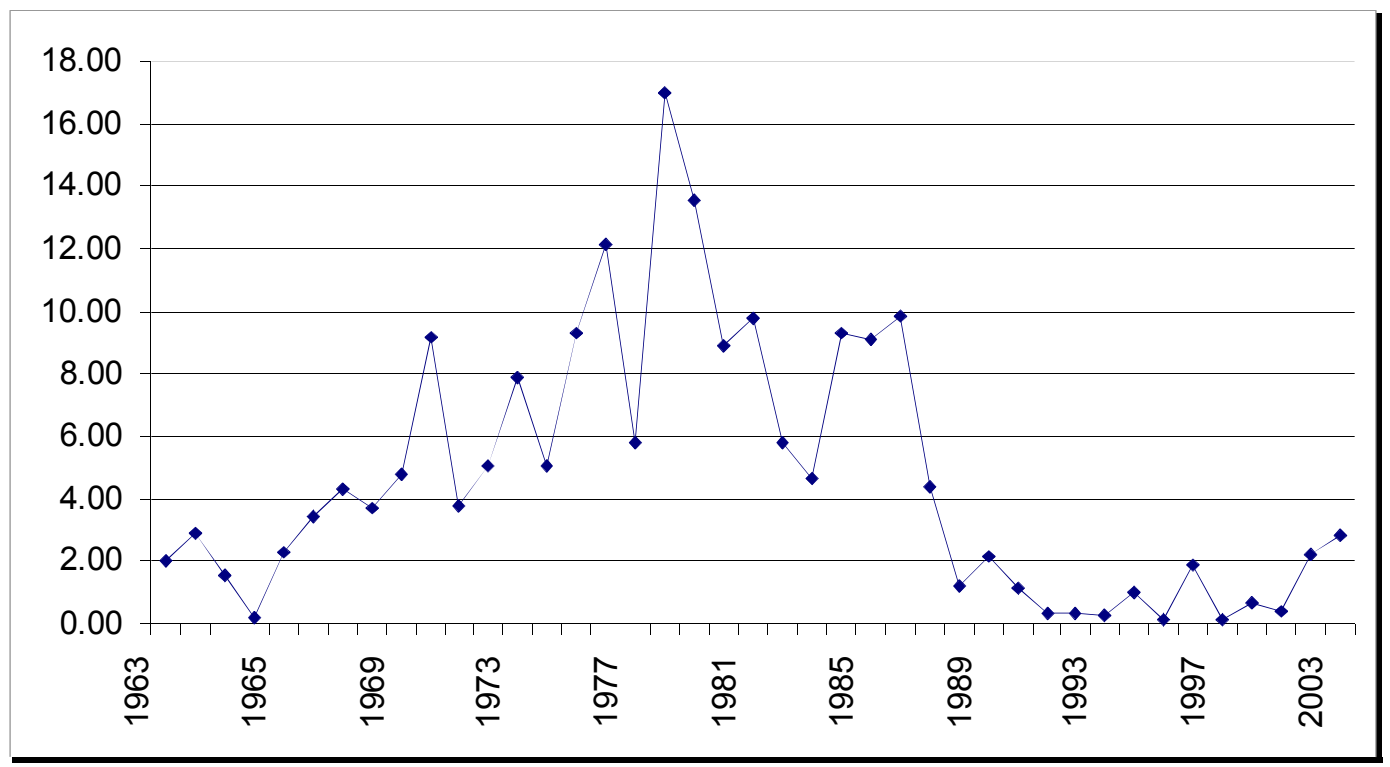

Fig. 5. The budget deficit as a percentage of GDP (percentage) Source: Based on the data from the Central Bank Of Islamic Republic of Iran

The ratio is 9.38 percent in the period of 1978-1988 (during the Iran-Iraq war) and decreases to 1.06 in the period of 1988 to 2003 (the years of the socio-economic development programs). The increase of the budget deficit in 1972 occurs while in these years, oil prices and oil revenues were increased, substantially. In 1974, with almost quadrupling the oil revenues and the total revenue growth of $199 \%$, the general government payments grow to $184 \%$. However general payments were lower in 
that year, its higher level in 52 caused to have the deficit in 53. Iran was heavily involved in the war with Iraq in 1981-1989 and so the high budget deficit could be somewhat normal in those years. However, in most years after that, that is 1990-2003, the budget deficit even went higher. Whatever the reasons and causes of this deficit were, the statistical researches show that the condition was rather dire in Iran and it can be a major reason for instability. The condition of budget deficit in Iran during the last four decades and be summarized as below:

1. The relatively high level of budget deficit rate, its rather upward trend in some certain intervals, and the relatively large range of fluctuations are three important features of the budget deficit in Iran.

2. Even during the peak of the oil revenue, still the deficit exists.

3. The budget deficit ratio increases after the revolution and during the first decade, it has been more than the second decade.

\section{Model}

In this section, using the presented theories, we first estimate the instability indexes clarifying the computed macroeconomic indexes and then the time series of the macroeconomic index.

\subsection{The estimation of the fractional ratio of budget deficit to GDP's}

To calculate the index of budget deficit to GDP fractional ratio, the instability index defined as "the deviation of real values from the estimated values" is used. First, an equation of degree $n$ on the basis of time is estimated so that we can calculate the budget deficit to GDP ratio.

$$
T B D_{t n}=\left(1.43 t-0.36 t^{2}+0.046 t^{3}-0.003 t^{4}+\left(5.8 \times 10^{-6}\right) t^{5}-\left(4.88 \times 10^{-8}\right) t^{6}+e_{t} \quad R^{2}=\% 73\right.
$$

All the coefficients are significant at less than 5 percent. The numbers in parentheses indicate the statistic $t, T B D_{m}$ is the measure of estimated budget deficit to GDP ratio, $t$ represents time degree $n$ and $e_{t}$ indicates perturbation sentence. Having estimated the values of the time process, we calculate the instability index of the of budget deficit to GDP ratio using the following formula:

$$
I B D_{t n}=B D_{t}-T B D_{t n},
$$

where $B D$ is the ratio of budget deficit to GDP (in constant prices of 1998) and $I B D_{m}$ is the ratio of budget deficit to GDP instability index. The data of the time series related to the budget deficit to GDP fractional ratio and the related instability index are calculated using Eq. (4). (See Table 1)

\section{Table 1}

The data of the time series related to the budget deficit to GDP fractional ratio and the related instability index in the period of 1963-2003.

\begin{tabular}{lll|lll|lll}
\hline Year & $\mathrm{BD}$ & $\mathrm{IBD}_{\text {tn }}$ & Year & $\mathrm{BD}$ & $\mathrm{IBD}_{\text {tn }}$ & Year & $\mathrm{BD}$ & $\mathrm{IBD}_{\text {tn }}$ \\
\hline 1963 & 2.04 & 1.2 & 1977 & 9.31 & -1.22 & 1992 & 2.16 & -0.84 \\
1964 & 2.9 & 1.19 & 1978 & 12.16 & 1.85 & 1993 & 1.18 & -1.00 \\
1965 & 1.58 & -1.4 & 1979 & 5.82 & -4.29 & 1994 & 0.32 & -1.19 \\
1966 & 0.19 & -4.49 & 1980 & 16.99 & 6.46 & 1995 & 0.33 & -1.09 \\
1967 & 2.33 & -0.86 & 1981 & 13.54 & 3.34 & 1996 & 0.29 & -0.41 \\
1968 & 3.43 & 0.75 & 1982 & 8.92 & -1.33 & 1997 & 0.99 & -0.80 \\
1969 & 4.29 & 2.16 & 1984 & 9.79 & -0.21 & 1998 & 0.12 & 0.64 \\
1970 & 3.71 & 1.01 & 1985 & 5.82 & -3.59 & 1999 & 1.89 & 2.80 \\
1971 & 4.77 & 1.55 & 1986 & 4.63 & -4.16 & 2000 & 0.10 & 0.13 \\
1972 & 9.16 & 6.99 & 1987 & 9.32 & 3.24 & 2001 & 0.69 & 0.21 \\
1973 & 3.81 & -2.16 & 1988 & 9.13 & 1.97 & 2002 & 0.39 & -0.98 \\
1974 & 5.08 & -2.88 & 1989 & 9.84 & 2.98 & 2003 & 2.21 & 0.11 \\
1975 & 7.92 & -1.38 & 1990 & 4.38 & 1.01 & 2004 & 2.86 & -0.17 \\
1976 & 5.04 & -4.17 & 1991 & 1.18 & -3.19 & & & \\
\hline
\end{tabular}




\subsection{The estimation of inflation rate instability}

To calculate the index of budget deficit to GDP fractional ratio, the instability index defined as "the deviation of real values from the estimated values" is used. First, an equation of degree $n$ on the basis of time is estimated so that we can calculate the time process of inflation rate.

$$
\operatorname{TINF}_{t n}=15.14-11.84 t+2.64 t^{2}-0.23 t^{3}+0.009 t^{4}-\left(1.8 \times 10^{-4}\right) t^{5}+\left(1.4 \times 10^{-7}\right) t^{6}+e_{t} \quad R^{2}=0.62
$$

All the coefficients are significant at less than 5 percent. The numbers in parentheses indicate the statistic $t, T I N F_{m}$ is the measure of estimated inflation rate index based on the form of degree $n$, $t$ represents time and $e_{t}$ denotes perturbation sentence. Having estimated the values of the time process, we calculate the instability index of the inflation rate using the following,

$$
I I N F_{t n}=I N F_{t}-T I N F_{t n},
$$

where $I N F_{t}$ represents the ratio of inflation rate and $I B D_{m}$ is the ratio of inflation rate instability index based on the form of degree $n$. The data of the time series related to the inflation rate index and the related instability index that are calculated using Eq. (6) are presented in Table 2.

\section{Table 2}

The data of the time series related to the inflation rate (INF) and the related instability index in the period of 1963-2003

\begin{tabular}{lll|lll|lll}
\hline Year & $\mathrm{INF}$ & $\mathrm{IINF}_{\text {tn }}$ & Year & $\mathrm{INF}$ & $\mathrm{IINF}_{\text {tn }}$ & Year & INF & IINF $_{\text {tn }}$ \\
\hline 1963 & 0.6 & -5.12 & 1977 & 24.9 & 9.69 & 1991 & 19 & -4.60 \\
1964 & 4 & 3.65 & 1978 & 10 & -5.40 & 1992 & 24.3 & -1.90 \\
1965 & 0 & 2.04 & 1979 & 11.3 & -4.20 & 1993 & 22.9 & -3.87 \\
1966 & 1 & 3.31 & 1980 & 23.6 & 8.01 & 1994 & 35.2 & 8.29 \\
1967 & 0.5 & 1.66 & 1981 & 23 & 7.26 & 1995 & 49.4 & 22.83 \\
1968 & 1 & 0.17 & 1982 & 19.2 & 3.19 & 1996 & 28.9 & 3.21 \\
1969 & 3 & -0.23 & 1983 & 14.8 & -1.66 & 1997 & 17.3 & -6.99 \\
1970 & 1 & -4.73 & 1984 & 10.04 & -6.7 & 1998 & 17.8 & -4.61 \\
1971 & 5.6 & -2.50 & 1985 & 6.9 & -11.06 & 1999 & 20.1 & -0.06 \\
1972 & 6.3 & -3.88 & 1986 & 23.7 & 4.7 & 2000 & 12.6 & -5.13 \\
1973 & 11.4 & -0.5 & 1987 & 27.7 & 7.49 & 2001 & 11.4 & -4.00 \\
1974 & 15.6 & 2.36 & 1988 & 28.9 & 7.38 & 2002 & 15.8 & 2.25 \\
1975 & 9.9 & -4.30 & 1989 & 17.4 & 17.4 & 2003 & 15.6 & 2.9 \\
1976 & 16.5 & 1.67 & 1990 & 9 & -15.1 & & & \\
\hline
\end{tabular}

\subsection{The estimation of exchange rate premium's instability index time series}

To calculate the instability index of exchange rate premium, first we estimate an equation of the form of degree $n$ on the basis of time (to compute the process of exchange rate premium). In this equation the exchange rate premium is considered a dependent variable, a function of the independent variable of time and the degrees of time $\mathrm{n}$. The results of the estimation of this equation are as follows:

$$
T R O_{t n}=-74.35+182.73 t-46.13 t^{2}+4.52 t^{3}-0.19 t^{4}+0.003 t^{5}-\left(2.92 \times 10^{6}\right) t^{6}+e_{t} \quad R^{2}=0.62
$$

All the coefficients are significant at less than 5 percent. The numbers in parentheses indicate the statistic $t$ and the variables used in the equation above are listed below:

$T R O_{m}=$ The measure of estimated exchange rate premium index based on the form of degree $n$.

Having estimated the values of the time process (the form of degree $n$ ), according to the instability index of "the deviation of real values from the estimated process", we calculate the instability index of the exchange rate premium using the following formula: 
where $E R O_{t}$ is the exchange rate premium and $I R O_{m}$ is the exchange rate premium instability index based on the form of degree $n$. The data of the time series related to the exchange rate premium index and the related exchange rate premium instability index are presented in Table 3.

\section{Table 3}

The data of time series related to the exchange rate premium (ERO) and the related exchange rate premium instability index $\left(I R O_{m}\right)$ over the period 1963-2003

\begin{tabular}{lll|lll|lll}
\hline Year & ERO & IRO $_{\text {tn }}$ & Year & ERO & IRO $_{\text {tn }}$ & Year & ERO & IRO $_{\text {tn }}$ \\
\hline 1963 & 128.82 & 97.60 & 1977 & 113.27 & -109.9 & 1991 & 300.2 & 10.18 \\
1964 & 115.23 & -34.08 & 1978 & 129.26 & -151.3 & 1992 & 236.4 & -29.65 \\
1965 & 115.30 & -77.56 & 1979 & 226.31 & -109.1 & 1993 & 161.05 & -92.24 \\
1966 & 11.49 & -77.29 & 1980 & 331.70 & -52.73 & 1994 & 148.7 & -103.8 \\
1967 & 109.03 & -49.11 & 1981 & 504.28 & 79.58 & 1995 & 139.79 & -34.23 \\
1968 & 110.6 & -6.40 & 1982 & 568.18 & 114.00 & 1996 & 147.81 & -34.55 \\
1969 & 112.94 & 35.91 & 1983 & 467.32 & -4.28 & 1997 & 158.98 & -47.82 \\
1970 & 112.46 & 66.33 & 1984 & 678.30 & 201.79 & 1998 & 119.88 & 13.82 \\
1971 & 111.74 & 82.62 & 1985 & 308.56 & -160.7 & 1999 & 109.49 & 111.21 \\
1972 & 108.56 & 80.37 & 1986 & 374.59 & -76.57 & 2000 & 101.36 & 77.16 \\
1973 & 109.80 & 66.30 & 1987 & 512.23 & 87.65 & 2001 & 101.09 & 98.16 \\
1974 & 108.9 & 35.30 & 1988 & 402.43 & 10.70 & 2002 & 100.76 & -165.6 \\
1975 & 110.07 & -5.83 & 1989 & 478.32 & 122.56 & 2003 & 100.5 & 18.38 \\
1976 & 113.32 & -53.73 & 1990 & 386.96 & 66.14 & & & \\
\hline
\end{tabular}

\subsection{The estimation of the instability index of foreign debt to GDP ratio time series}

To calculate the index of foreign debt to GDP ratio, the instability index defined as "the deviation of real values from the estimated process" is used. First, an equation of degree $n$ on the basis of time is estimated so that we can calculate the time process of foreign debt to GDP ratio.

$$
T F D_{t n}=\left(2.59-2.26 t+0.55 t^{2}-0.049 t^{3}+0.002 t^{4}-\left(3.87 \times 10^{6}\right) t^{5}+\left(2.87 \times 10^{8}\right)+e_{t} \quad R^{2}=0.81\right.
$$

All the coefficients are significant at less than 5 percent. The numbers in parentheses indicate the statistic $t$ and $T F D_{m}=$ The measure of estimated foreign debt to GDP ratio index based on the form of degree $n, t$ represents time and $e_{t}$ is the perturbation sentence. Having estimated the values of the time process, we calculate the instability index of foreign debt to GDP ratio using the following,

$I F D_{t n}=F D_{t}-T F D_{t n}$,

where $F D_{t}$ is the ratio of foreign debt to GDP ratio (in the fixed price of 1997) and $I F D_{m}$ is the ratio of foreign debt to GDP ratio instability index based on the form of degree $n$. The data of the time series related to the foreign debt to GDP ratio index and the related instability index that are calculated using Eq. (10) are presented in Table 4.

\subsection{The estimation of macroeconomics instability index time series (MII)}

In order to calculate the "macroeconomics instability index", we use the definition of Fischer and Bleaney. These economists introduce a simple average of the four variables of inflation index, of budget deficit to GDP ratio, foreign debt to GDP ratio and the exchange rate changes as the macroeconomics instability indexes (Ismihan et al., 2005). To estimate the macroeconomics instability index time series (MII), the estimated instability time series in this chapter are used; and regarding the estimated processes, we can obtain the macroeconomics instability index time series of the form of degree $n$. 
$\mathrm{MII}_{\mathrm{tn}}=\frac{\sum\left(I I N F_{t n}, I B D_{t n}, I F D_{t n}, I R O_{t n}\right)}{N}$,

where $\mathrm{MII}_{\mathrm{tn}}$ represents macroeconomics instability index, $\mathrm{IINF}_{\mathrm{tn}}$ denotes inflation rate instability index, $\mathrm{IBD}_{\mathrm{tn}}$ indicates the fractional ratio of budget to GDP instability index, IFD $_{\mathrm{tn}}$ is associated with the ratio of budget deficit to GDP instability index and finally $\mathrm{IRO}_{\mathrm{tn}}$ represents exchange rate premium instability index.

\section{Table 4}

The data of the time series related to the foreign debt to GDP ratio $\left(\mathrm{FD}_{\mathrm{t}}\right)$ and the related instability index over the period 1963-2003

\begin{tabular}{lll|lll|lll}
\hline Year & $\mathrm{FD}_{\mathrm{t}}$ & $\mathrm{IFD}_{\mathrm{tn}}$ & Year & $\mathrm{FD}_{\mathrm{t}}$ & $\mathrm{IFD}_{\mathrm{tn}}$ & Year & $\mathrm{FD}_{\mathrm{t}}$ & $\mathrm{IFD}_{\mathrm{tn}}$ \\
\hline 1963 & 0.09 & -0.11 & 1977 & 3.458 & 0.06 & 1991 & 0.266 & 0.01 \\
1964 & 0.188 & 0.04 & 1978 & 2.993 & 0.09 & 1992 & 0.140 & 0.04 \\
1965 & 0.298 & 0.09 & 1979 & 2.371 & 0.10 & 1993 & 0.249 & 0.14 \\
1966 & 0.398 & 0.09 & 1980 & 2.078 & 0.11 & 1994 & 0.162 & 0.18 \\
1967 & 0.450 & 0.05 & 1981 & 1.692 & 0.11 & 1995 & 0.059 & 0.17 \\
1968 & 0.517 & 0.01 & 1982 & 0.0012 & 0.03 & 1996 & 0.092 & 0.19 \\
1969 & 0.654 & -0.04 & 1983 & 0.001 & 0.0 & 1997 & 0.15 & 0.15 \\
1970 & 1.641 & -0.06 & 1984 & 0.0019 & -0.03 & 1998 & 0.171 & -0.03 \\
1971 & 1.606 & -0.08 & 1985 & 0.0027 & -0.06 & 1999 & 0.159 & -0.47 \\
1972 & 1.625 & -0.08 & 1986 & 0.0031 & -0.09 & 2000 & 0.611 & -0.47 \\
1973 & 2.064 & -0.07 & 1987 & 0.0043 & -0.12 & 2001 & 0.747 & -0.99 \\
1974 & 3.268 & -0.04 & 1988 & 0.001 & -0.13 & 2002 & 2.777 & 1.96 \\
1975 & 4.708 & 0.01 & 1989 & 0.0012 & -0.12 & 2003 & 2.296 & -0.73 \\
1976 & 3.336 & -0.02 & 1990 & 0.046 & -0.09 & & & \\
\hline
\end{tabular}

Time series data of macroeconomics instability index which are calculated using Eq. (11) are presented in Table 5 .

\section{Table 5}

Time series' data related to the four indexes used in macroeconomics instability index and the computation of $\mathrm{MII}_{\mathrm{tn}}$

\begin{tabular}{llllll|llllll}
\hline Year & $\mathrm{IRO}_{\text {tn }}$ & $\mathrm{IINF}_{\text {tn }}$ & $\mathrm{IBD}_{\text {tn }}$ & $\mathrm{IFD}_{\text {tn }}$ & $\mathrm{MII}_{\text {tn }}$ & Year & $\mathrm{IRO}_{\text {tn }}$ & $\mathrm{IINF}_{\text {tn }}$ & $\mathrm{IBD}_{\text {tn }}$ & $\mathrm{IFD}_{\text {tn }}$ & $\mathrm{MII}_{\mathrm{tn}}$ \\
\hline 1963 & 97.6 & -5.1 & 1.2 & -0.1 & 23.3 & 1983 & -4.28 & -1.66 & -0.21 & 0 & -1.54 \\
1964 & -34 & 3.6 & 1.1 & 0.04 & -7.3 & 1984 & 201.7 & -6.7 & -3.59 & -0.03 & 47.8 \\
1965 & -77 & 2.4 & -1.4 & 0.09 & -19.2 & 1985 & -160 & -11 & -4.16 & -0.06 & -24.2 \\
1966 & -77.2 & 3.3 & -4.4 & 0.09 & -19.6 & 1986 & -75.7 & 4.7 & 3.24 & -0.09 & -17.1 \\
1967 & -49.1 & 1.66 & -0.86 & 0.05 & 12 & 1987 & 87.6 & 7.49 & 1.97 & -0.12 & 24.2 \\
1968 & -6.4 & 0.1 & 0.75 & 0.01 & -1.37 & 1988 & 10.7 & 7.38 & 6.14 & -0.13 & 6.21 \\
1969 & 35.9 & -0.2 & 2.16 & -0.04 & 9.45 & 1989 & 122.5 & -5.46 & 0.01 & -0.12 & 29.3 \\
1970 & 66.3 & -4.7 & 1.01 & -0.06 & 15.6 & 1990 & 66.14 & -15.1 & -3.19 & -0.09 & 11.9 \\
1971 & 82.6 & -2.5 & 1.55 & -0.08 & 20.4 & 1991 & 10.18 & -4.60 & -0.84 & 0.01 & 1.19 \\
1972 & 80.3 & -3.8 & 6.99 & -0.08 & 20.8 & 1992 & -29.65 & -1.9 & -1.0 & 0.04 & -8.13 \\
1973 & 66.3 & -0.5 & -2.16 & -0.07 & 15.8 & 1993 & -92.24 & -3.87 & -1.19 & 0.14 & -24.2 \\
1974 & 35.3 & 2.3 & -2.88 & -0.04 & 8.69 & 1994 & -103.8 & 8.29 & -1.09 & 0.18 & -24.1 \\
1975 & -5.83 & -4.3 & -1.38 & 0.01 & -2.88 & 1995 & -33.2 & 22.8 & -0.41 & 0.17 & -2.66 \\
1976 & -53.7 & 1.67 & -4.17 & -0.01 & -14.0 & 1996 & -34.55 & 3.21 & -0.8 & 0.19 & -7.99 \\
1977 & -109.9 & 9.69 & -1.23 & 0.06 & -25.3 & 1997 & -47.87 & -6.99 & 0.64 & 0.15 & -13.5 \\
1978 & -151.39 & -5.40 & 1.85 & 0.09 & -38.7 & 1998 & 13.82 & -4.61 & 2.80 & -0.03 & 3.00 \\
1979 & -109.18 & -4.20 & -4.93 & 0.10 & -29.5 & 1999 & 111.2 & -0.06 & 0.13 & -0.47 & 27.71 \\
1980 & -52.73 & 8.0 & 6.64 & 0.11 & -9.54 & 2000 & 77.16 & -5.13 & 0.21 & -0.26 & 17.99 \\
1981 & 79.5 & 7.26 & 3.33 & 0.11 & 22.5 & 2001 & 98.16 & -4.00 & -0.98 & -0.99 & 23.0 \\
1982 & 114.0 & 3.19 & -1.37 & 0.03 & 28.9 & 2002 & -165.6 & 2.25 & 0.11 & 1.96 & -40.3 \\
& & & & & & 2003 & 18.38 & 2.90 & -0.17 & -0.73 & 5.09 \\
\hline
\end{tabular}

\section{Conclusion}

In this research, we have studied the condition of stability or instability Iran's economy using four indexes of budget deficit, inflation rate, exchange rate and foreign debt. 
6.1. Budget deficit: The deficit in the years 1963-2003 did not have an entirely increasing trend, however, such a trend is observed in some certain intervals: between 1963-72 the ratio of budget deficit with some fluctuations moved from 2.04 percent to 9.16 percent. The same trend is also seen in 1973-78 from 3.18 to 12.16 percent. Chart shows the range of fluctuations of the budget deficit has generally been rising from 1963 to 1981. In the subsequent years of 1981 to 2003, the changes in the budget deficit ratio rather than this increasing trend are observed in some years.

6.2. Exchange Rate: There are several indicators to show the stability or instability of exchange rates; one of which is the ratio of free exchange rate to official exchange rate, and it is known as the exchange rate premium. The exchange rate premium had a stable and consistent condition in years 1963-1986. The percentage changes in the exchange rate premium in these years were 1.14 percent, although the fluctuations increase slightly since 1974. The fluctuation in exchange rate premium were considerable in the period of 1979-2003. Percentage change in the exchange rate premium in this period increased to 3.53 times more than before.

6.3. Inflation rate: The average rate of inflation was 6.96 percent in the period of $1963-1978$. In the years after the Revolution, that is 1979-2003, it became 30.32 percent, at Gap, and in 1980-1988, it was 19.8 percent.

6.4. Foreign Debt: The biggest portion in the composition of Iran's external debt belongs to shortterm debts and we are observing a rising trend in foreign debt from 1999 to 2003.

\section{References}

Agénor, P. R. (2004). The economics of adjustment and growth. La Editorial, UPR.

Bleaney, M. F. (1996). Macroeconomic stability, investment and growth in developing countries. Journal of development economics, 48(2), 461-477.

Fischer, S. (1991). Growth, macroeconomics, and development. In NBER Macroeconomics Annual 1991, Volume 6 (pp. 329-379). MIT Press.

Fischer, S., \& Modigliani, F. (1978). Towards an understanding of the real effects and costs of inflation. Weltwirtschaftliches Archiv, 114(4), 810-833.

Glezakos, C. (1973). Export instability and economic growth: A statistical verification. Economic Development and Cultural Change, 21(3), 670-678.

Hadjimichael, M., Ghura, D., Mühleisen, M., Nord, R., \& Ucer, E. M. (1994). Effects of macroeconomic stability on growth, savings, and investment in Sub-Saharan Africa: An empirical investigation.

IMF (1990). World Economic Outlook,Dec.1990.

IMF (1998). World Economic Outlook and International Market Interim Assessment, Dec. 1998

Ismihan, M., Metin-Ozcan, K., \& Tansel, A. (2005). The role of macroeconomic instability in public and private capital accumulation and growth: the case of Turkey 1963-1999. Applied Economics, 37(2), 239-251.

Oshikoya, T. W. (1994). Macroeconomic determinants of domestic private investment in Africa: An empirical analysis. Economic development and cultural change, 42(3), 573-96.

Rangriz, H., \& Khorshidi, G. H. (2008). Management Information System Analysis and Design. Tehran: Bazargani Publishing, 84.

Rodrik, D. (1991). Policy uncertainty and private investment in developing countries. Journal of Development Economics, 36(2), 229-242.

Tanzi, V., \& Davoodi, H. (1998). Corruption, public investment, and growth (pp. 41-60). Springer Japan.

World Bank (1991). World Development Report. 1-6, 155-157.

World Bank (1993). The East Asian economic miracle: Economic growth and public policy. 